\title{
FAKTOR-FAKTOR YANG MEMPENGARUHI ANOMALI PASAR CABAI RAWIT DI KOTA CIREBON
}

\author{
Wachdijono $^{1}$ dan Akhmad Jaeroni ${ }^{2}$ \\ ${ }^{1}$ Program Studi Agribisnis Fakultas Pertanian UGJ Cirebon \\ ${ }^{2}$ Program Studi Agribisnis Fakultas Pertanian UGJ Cirebon \\ e-mail:wadiono1113@gmail.com / wajo0413@gmail.com
}

\begin{abstract}
Abstrak
Penelitian ini bertujuan untuk mengetahui faktor-faktor yang mempengaruhi anomali pasar cabai rawit di Kota Cirebon. Metode penelitian yang digunakan adalah kuantitatif dengan menggunakan teknik pendekatan survei. Lokasi penelitian ditentukan secara sengaja yaitu di Pasar Rakyat Jagasatru, Pasar Kalitanjung dan Pasar Kanoman Kota Cirebon. Penelitian dilaksanakan pada bulan Januari sampai dengan Agustus 2019. Adapun populasinya yaitu pedagang cabai rawit, tomat, terasi, garam dan bawang merah, serta petani cabai rawit di sentra produksi. Penentuan besar sampel dilakukan secara sengaja sehingga penarikan sampel berdasarkan quota sampling, yaitu masing-masing sebesar 30 orang. Analisis data dilakukan dengan menggunakan instrumen analisis regresi linier berganda, pengolahan data menggunaan aplikasi program SPSS dan pengujian hipotesis menggunakan uji $\mathrm{F}$ dan uji T. Hasil penelitian menunjukkan bahwa secara simultan faktor jumlah produk, harga bawang merah, harga tomat, harga terasi, harga garam, musim dan harga input berpengaruh terhadap anomali pasar cabai rawit di pasar Kota Cirebon, sedangkan secara parsial faktor jumlah produk dan harga input yang berpengaruh. Untuk itu disarankan adanya kebijakan percabaian yang dirumuskan oleh pemerintah Kota Cirebon berdasarkan faktor yang berpengaruh secara parsial tersebut.
\end{abstract}

Kata kunci: anomali, cabai rawit, harga, kebijakan.

\begin{abstract}
This study aims to determine the factors that influence the anomaly of chili market in Cirebon City. The research method used is quantitative using survey approach techniques. The research location was determined intentionally, namely the Jagasatru People's Market, Kalitanjung Market and Kanoman Market. The study was conducted in January to August 2019. The population was traders of chili, tomatoes, shrimp paste, salt and shallots, as well as farmers of chili in the production center. Determination of the size of the sample is done deliberately so that the withdrawal of the sample is based on a quota sampling, which is 30 people each. Data analysis was performed using multiple linear regression analysis instruments, data processing using the SPSS program application and hypothesis testing using the F test and $T$ test. The results showed that the simultaneous factor of the number of products, the price of shallot, the price of tomatoes, the price of shrimp paste, the price of salt, season and input prices affect the anomaly of the chili market in the Cirebon City market, while partially the number of products and input price factors influence. For this reason, it is suggested that a policy of divorce be formulated by the Cirebon city government based on the factors that partially influence it.
\end{abstract}

Keywords: anomaly, chili, policy, price 


\section{Pendahuluan}

Cabai rawit (Capsicum frutescens $\mathrm{L}$ ) adalah salah satu produk pertanian hortikultura yang sangat digemari oleh masyarakat Indonesia. Rasanya yang pedas alami merupakan kunci utama pelengkap menu yang menjadikan masakan lebih enak, lebih nikmat dan lebih berselera.Oleh karena itu, kedudukannya sebagai pelengkap menu (dalam bentuk sambal), tak dapat terhindarkan dalam setiap penyajian masakan/makanan pokok sehari-hari, artinya keberadaan sambal tersebut harus tetap ada. Kegemaran masyarakat terhadap cabai rawit sebagai bahan baku sambal, tiap tahunnya meningkat. Hal ini dikarenakan belum adanya barang subtitusi yang sempurna terhadap cabai rawit, meningkatnya jumlah penduduk dan peningkatan pendapatan masyarakat. Untuk mengetahui peningkatannya dapat dilihat pada Tabel 1.

\section{Tabel 1}

\section{Hasil Proyeksi Permintaan Cabai Rawit Indonesia Tahun 2015-2019}

\begin{tabular}{cccc}
\hline Tahun & $\begin{array}{c}\text { Konsumsi } \\
(\text { Kg/Kapita } \\
\text { /Thn) }\end{array}$ & $\begin{array}{c}\text { Jumlah } \\
\text { Penduduk } \\
\text { (Orang) }\end{array}$ & $\begin{array}{c}\text { Total } \\
\text { Konsumsi } \\
\text { (Ton) }\end{array}$ \\
\hline 2015 & 1,32 & 255.462 & 335.968 \\
2016 & 1,35 & 258.705 & 350.183 \\
2017 & 1,39 & 261.891 & 364.570 \\
2018 & 1,43 & 265.015 & 379.112 \\
2019 & 1,47 & 267.974 & 393.654 \\
\hline $\begin{array}{c}\text { Rata-Rata } \\
\text { Pertumbuhan } \\
\text { (\%/th) }\end{array}$ & 2,80 & 1,2044 & 4,04 \\
\hline
\end{tabular}

Sumber: Pusat Data dan Sistem Informasi Pertanian Sekretariat Jenderal Kementerian Pertanian Tahun 2015-2019.

Tabel 1 menunjukkan bahwa proyeksi konsumsi cabai rawit dari tahun ke tahun pada periode tahun 2015 - 2019 adalah meningkat sehingga menempatkan komoditas cabai rawit pada posisi produk yang dibutuhkan masyarakat. Oleh karenanya berapapun tinggi harganya tetap akan dibeli. Memasuki periode tahun
2015 - 2018 ini, komoditas cabai rawit selain terus digemari, juga menjadi sangat populer di seluruh penjuru Indonesia. Kepopuleran ini dikarenakan hampir setiap menjelang hari raya idul fitri dan memasuki musim hujan atau mengakhiri musim kemarau, harga jualnya selalu tinggi di pasaran, baik di pasaran lokal maupun nasional. Sebagai contoh (sampel) adalah kenaikkan harga jual cabai rawit di pasaran Kota Cirebon, Provinsi Jawa Barat, berkisar $400 \%$ sd $1.000 \%$ pada periode tahun 2017 (Survai Pendahuluan, Mei 2018).

Kenaikkan harga cabai rawit yang tinggi di atas menunjukkan adanya peristiwa ekonomi yang tidak sewajarnya atau dikenal dengan telah terjadinya anomali pasar cabai rawit. Anomali pasar ini terjadi karena dipengaruhi oleh beberapa faktor (variabel ekonomi) yang belum teridentifikasikan secara jelas (signifikan). Walaupun demikian, peristiwa anomali pasar tidak boleh dibiarkan terlalu panjang (lama) karena akan berdampak lebih serius lagi pada aspek ekonomi (inflasi), aspek sosial (kriminalitas) dan budaya (cobweb). Terbukti pada tahun 2017, cabai rawit telah berkontribusi pada laju inflasi di Indonesia sebesar 0,05 \% (BPS, 2017), sering terjadi tindak pencurian cabai di lahan (kriminal) karena harga tinggi di pasaran, dan timbulnya budaya latah (ikut-ikutan) dalam budidaya cabai rawit. Mengingat adanya dampak negatif tersebut, maka diperlukan penanganan segera secara efektif dan berkelanjutan oleh pihak-pihak yang berkompoten, terutama Pemerintah Kota Cirebon melalui Dinas Pertanian terkait. Fluktuasi harga yang tinggi juga tidak menguntungkan bagi pengembangan agribisnis hortikultura (Nurvitasari et al., 2018).

Penelitian sebelumnya yang berhubungan dengan penelitian ini, antara lain: Riyadh, et al. (2018), Rahmah et al., (2017), Saptana et al., (2012) dan Nurvitasari et al., (2018). 
Hasil penelitian Riyadh, et al. (2018) menyimpulkan perkembangan harga cabai rawit hijau selama tahun 2014-2017 mengalami fluktuatif setiap bulan dan dalam jangka pendek memberikan dampak inflasi yang nyata di kota Medan, sedangkan Bank Negara Indonesia (2015) dalam Rahmah et al. (2017), menyebutkan bahwa pada bulan April-Juni 2015, komoditas cabai menyumbang inflasi sebesar $78 \%$, dimana besar inflasi tersebut mengalahkan komoditas pangan dan non pangan. Kondisi yang demikian selaras dengan hasil penelitian Saptana et al. (2012) yang menyimpulkan bahwa fluktuasi harga cabai merah yang tinggi disebabkan fluktuasi produksi antar waktu (bulan dan musim), sedangkan Eka et al., (2018) memprediksi harga cabai merah di Jember tahun 20172018 akan mengalami fluktuasi setiap bulannya. Adapun tujuan dari penelitian ini adalah untuk mengetahui faktor-faktor yang mempengaruhi anomali (fluktuasi harga) pasar cabai rawit di Kota Cirebon Provinsi Jawa Barat. Hasil dari penelitian diharapkan dapat mengidentifikasi faktor-faktor yang secara nyata mempengaruhi anomali pasar cabai rawit secara parsial sehingga dapat menjadi bahan masukan kepada Pemerintah Kota Cirebon dalam merumuskan kebijakan yang relevan dan efektif untuk mencegah terjadinya anomali pasar cabai rawit dan dampak negatifnya ke depan.

\section{Metode Penelitian}

Lokasi penelitian ditentukan secara sengaja (purposive) yaitu pada tiga pasar di Kota Cirebon, yaitu di Pasar Rakyat Jagasatru, Pasar Kanoman dan Pasar Kalitanjung, dengan dasar pertimbangan bahwa ke tiga pasar tersebut merupakan pasar hortikultura sayuran terbesar sehingga dapat dinilai sebagai representasi pasar-pasar lain di Kota Cirebon. Penelitian ini dilaksanakan pada bulan Januari sampai dengan Agustus 2019.

Desain penelitian ini adalah kuantitatif dengan menggunakan teknik pendekatan survei. Data diperoleh melalui wawancara berdasarkan kuesioner, kemudian dilakukan analisis secara kuantitatif melalui pengujian hipotesis.

Populasi dalam penelitian ini adalah pedagang cabai rawit, pedagang tomat, pedagang terasi, pedagang garam dan pedagang bawang merah yang berjualan di Pasar Jagasatru, Pasar Kanoman dan Pasar Kalitanjung Kota Cirebon, serta petani cabai rawit di sentra produksi. Penentuan besar sampel dilakukan secara sengaja dengan pertimbangan bahwa jumlah dimaksud sudah dapat mewakili sehingga penarikan sampel berdasarkan quota sampling. Dengan demikian besar sampel masing-masing ditentukan sebesar 30 orang pedagang cabai rawit, 30 orang pedagang tomat, 30 orang pedang terasi, 30 orang pedagang garam, 30 orang pedagang bawang merah dan 30 orang petani cabai rawit.

Dalam penelitian ini ditetapkan variabel penelitian yang relevan dengan tujuan penelitian, sebagai berikut:

a. Harga jual cabai rawit (Anomali) adalah harga cabai rawit dari pedagang di Pasar Jagasatru ke konsumen, yang dinyatakan dalam $\mathrm{Rp} / \mathrm{kg} / \mathrm{musim}$

b. Jumlah produk adalah jumlah produk cabai rawit dijual di Pasar Jagasatru, yang dinyatakan dalam $\mathrm{kg} /$ orang

c. Harga tomat adalah harga jual tomat oleh pedagang di pasar, yang dinyatakan dalam $\mathrm{Rp} / \mathrm{kg}$

d. Harga bawang merah adalah harga yang dijual oleh pedagang di pasar, yang dinyatakan dalam $\mathrm{Rp} / \mathrm{kg}$

e. Harga terasi adalah harga jual terasi oleh pedagang di pasar, yang dinyatakan dalam Rp/bungkus

f. Harga garam adalah harga yang dijual pedagang di pasar, yang dinyatakan dalam Rupiah/pak

g. Musim adalah waktu tanam dan waktu panen cabai rawit selama periode tanam 
dalam 12 bulan, yang dinyatakan variabel dummy yaitu $0=$ musim panen dan 1 = musim paceklik

h. Harga input adalah biaya untuk membeli input (pupuk, obat-obatan, bibit, tenaga kerja) selama periode tanam hingga panen, yang dintakan $\mathrm{Rp} / \mathrm{kg}$.

Untuk memperjelas konsep pengukuran variabel di atas, maka dapat dilihat pada Tabel 2 berikut ini.

Tabel 2

Operasionalisasi Variabel

\begin{tabular}{lll}
\hline Variabel & Satuan & $\begin{array}{l}\text { Skala } \\
\text { Data }\end{array}$ \\
\hline $\begin{array}{l}\text { Jumlah produk } \\
\text { cabai rawit }\left(\mathrm{X}_{1}\right)\end{array}$ & Kg/Orang & Rasio \\
$\begin{array}{l}\text { Harga tomat }\left(\mathrm{X}_{2}\right) \\
\text { Harga bawang } \\
\text { merah }\left(\mathrm{X}_{3}\right)\end{array}$ & $\begin{array}{l}\text { Rupiah/kg } \\
\text { Rupiah/kg }\end{array}$ & $\begin{array}{l}\text { Rasio } \\
\text { Rasio }\end{array}$ \\
$\begin{array}{l}\text { Harga terasi }\left(\mathrm{X}_{4}\right) \\
\text { Harga garam }\end{array}$ & $\begin{array}{l}\text { Rupiah/bungkus } \\
\text { Rupiah/pak }\end{array}$ & $\begin{array}{l}\text { Rasio } \\
\text { Rasio }\end{array}$ \\
$\begin{array}{l}\text { Musim }\left(\mathrm{X}_{6}\right) \\
\begin{array}{l}\text { Harga } \\
\text { memperoleh } \\
\text { input }\left(\mathrm{X}_{7}\right)\end{array}\end{array}$ & $\begin{array}{l}\text { Dummy } \\
\text { Rupiah/kg }\end{array}$ & Nominal \\
$\begin{array}{l}\text { Anomali cabai } \\
\text { rawit }(\mathrm{Y})\end{array}$ & Rupiah/kg & Rasio \\
\hline
\end{tabular}

\section{Metode Analisis Data}

Dalam menganalisis faktor-faktor yang mempengaruhi anomali pasar cabai rawit di pasar Jagasatru Kota Cirebon, digunakan instrumen analisis regresi linier berganda.Analisis ini digunakan untuk mengukur pengaruh variabel independen $\left(\mathrm{X}_{1}, \mathrm{X}_{2}, \mathrm{X}_{3}, \mathrm{X}_{4}, \mathrm{X}_{5}, \mathrm{X}_{6}\right.$ dan $\left.\mathrm{X}_{7}\right)$ terhadap variabel dependen $(\mathrm{Y})$, baik secara simultan maupun secara parsial. Adapun rumus persamaannya, yaitu:

$\mathrm{Y}=\mathrm{b}_{0}+\mathrm{b}_{1} \mathrm{X}_{1}+\mathrm{b}_{2} \mathrm{X}_{2}+\mathrm{b}_{3} \mathrm{X}_{3}+\mathrm{b}_{4} \mathrm{X}_{4}+\mathrm{b}_{5}$

$\mathrm{X}_{5}+\mathrm{b}_{6} \mathrm{X}_{6}+\mathrm{b}_{7} \mathrm{X}_{7}+\mathrm{e}$

Dimana:

$$
\begin{aligned}
& \mathrm{Y}= \begin{array}{l}
\text { Anomali pasar/harga cabai rawit } \\
(\mathrm{Rp} / \mathrm{kg})
\end{array} \\
& \mathrm{b}_{\mathrm{o}}= \text { Koefisien Intersep / konstanta } \\
& \mathrm{X}_{1}=\text { Jumlah produk/produsen (kg/orang) } \\
& \mathrm{X}_{2}=\text { Harga Tomat }(\mathrm{Rp} / \mathrm{Kg})
\end{aligned}
$$

$$
\begin{aligned}
\mathrm{X}_{3} & =\text { Harga Bawang Merah (Rp/Kg) } \\
\mathrm{X}_{4} & =\text { Harga Garam (Rp/bungkus) } \\
\mathrm{X}_{5} & =\text { Harga Terasi (Rp/bungkus) } \\
\mathrm{X}_{6} & =\text { Musim (0:musim panen, 1:paceklik) } \\
\mathrm{X}_{7} & =\text { Harga memperoleh input (Rp/Kg) } \\
\mathrm{b}_{1} & =\text { Koefisisen regresi pada variabel } \mathrm{X}_{1} \\
\mathrm{~b}_{2} & =\text { Koefisisen regresi pada variabel } \mathrm{X}_{2} \\
\mathrm{~b}_{3} & =\text { Koefisisen regresi pada variabel } \mathrm{X}_{3} \\
\mathrm{~b}_{4} & =\text { Koefisisen regresi pada variabel } \mathrm{X}_{4} \\
\mathrm{~b}_{5} & =\text { Koefisisen regresi pada variabel } \mathrm{X}_{5} \\
\mathrm{~b}_{6} & =\text { Koefisisen regresi pada variabel } \mathrm{X}_{6} \\
\mathrm{~b}_{7} & =\text { Koefisisen regresi pada variabel } \mathrm{X}_{7} \\
\mathrm{e} & =\text { Standar eror }
\end{aligned}
$$

(Riduan, 2011; Sugiyono, 2017).

\section{Teknik Pengolahan Data dan Pengujian Hipotesis}

Teknik pengolahan data menggunaan alat bantu komputer dan aplikasi program SPSS (Statistical Package for the Social Sciences), sedangkan pengujian hipotesis dilakukan dengan menggunakan uji $\mathrm{F}$ dan uji T.

\section{Koefisien Determinasi $\left(r^{2}\right)$}

Koefisien determinasi $\left(r^{2}\right)$ bertujuan untuk mengetahui besarnya kontribusi atau keefektifan model dari suatu struktur variabel (faktor) $X_{1}, X_{2}, X_{3} \mathrm{daX}_{2}, \mathrm{X}_{3}, \mathrm{X}_{4}, \mathrm{X}_{5}$, $\mathrm{X}_{6}$, dan $\mathrm{X}_{7}$ (independen) terhadap variabel $\mathrm{Y}$ (dependen).

$K d=r^{2} \times 100 \%$

Dimana:

$\mathrm{Kd}=$ Koefisien Determinasi;

$r^{2}=$ Koefisien Korelasi

(Riduan, 2011; Sugiyono, 2017).

\section{Hasil dan Pembahasan}

\section{Model Persamaan Regresi Linier Berganda}

Berdasarkan analisis regresi terhadap datadata penelitian yang menggunaan alat bantu program SPSS diperoleh gambaran hasil koefisien regresi sebagaimana terlihat pada Tabel 3. 
Tabel 3

Koefisien Regresi pada Variabel Independen dan Nilai Signifikasinya

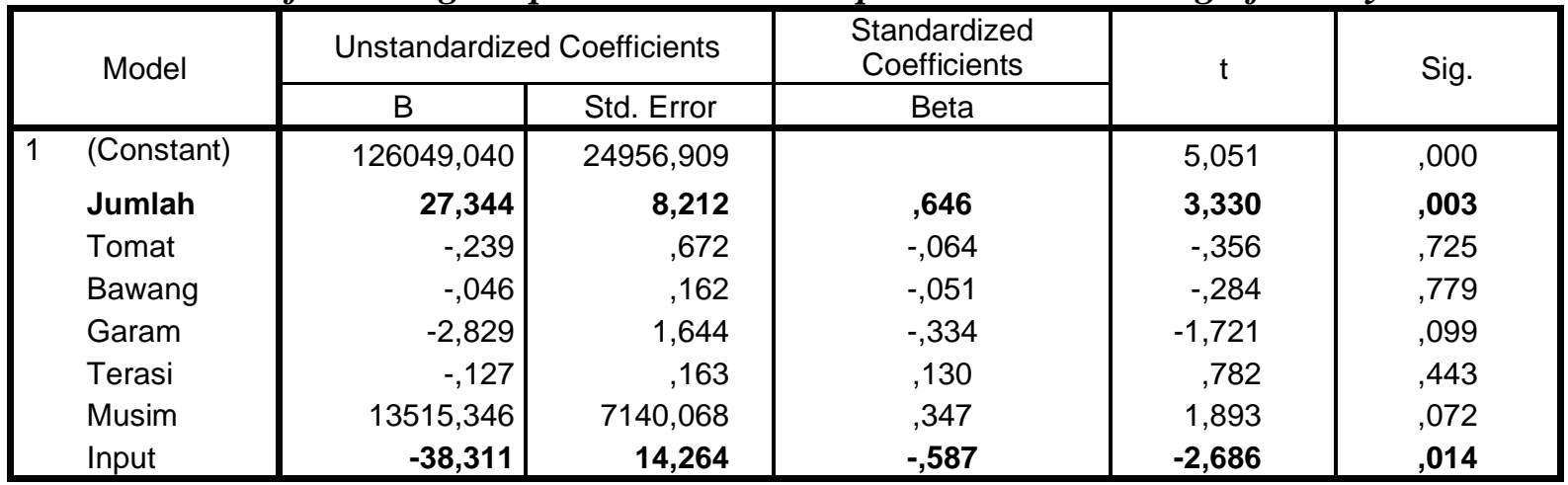

a. Dependent Variable: Anomali

Data primer diolah SPSS (2019)

Tabel 3 menunjukkan nilai-nilai koefisien regresi sehingga dapat membentuk suatu persamaan regresi linier berganda, yaitu:

$$
\begin{aligned}
\mathrm{Y}= & 126.049+27,344 \mathrm{X}_{1}-0,239 \mathrm{X}_{2}- \\
& 0,046 \mathrm{X}_{3}-2,829 \mathrm{X}_{4}-0,127 \mathrm{X}_{5}+ \\
& 13515,346 \mathrm{X}_{6}-38,311 \mathrm{X}_{7}
\end{aligned}
$$

Dimana :

$\mathrm{Y}=$ Anomali pasar/harga cabai rawit $(\mathrm{Rp} / \mathrm{kg})$

$\mathrm{b}_{0} \quad=$ Koefisien Intersep / konstanta

$\mathrm{X}_{1} \quad=$ Jumlah produk/produsen $(\mathrm{kg} / \mathrm{orang})$

$\mathrm{X}_{2} \quad=$ Harga Tomat $(\mathrm{Rp} / \mathrm{Kg})$

$\mathrm{X}_{3} \quad=$ Harga Bawang Merah $(\mathrm{Rp} / \mathrm{Kg})$

$\mathrm{X}_{4} \quad=$ Harga Garam (Rp/bungkus)

$\mathrm{X}_{5} \quad=$ Harga Terasi (Rp/bungkus)

$\mathrm{X}_{6}=\operatorname{Musim}(0:$ musim panen, 1:paceklik)

$\mathrm{X}_{7} \quad=$ Harga memperoleh input $(\mathrm{Rp} / \mathrm{Kg})$

\section{Uji Validitas Model Persamaan Regresi}

Berdasarkan hasil uji secara simultan dengan uji $\mathrm{F}$, bahwa nilai $\mathrm{F}$ Hitung sebesar 2,557 lebih besar dibandingkan dengan nilai $F$ Tabel yaitu sebesar 2,49, sehingga persamaan regresi tersebut di atas signifikan dan dapat digunakan untuk memprediksi nilai variabel Y (anomali/fluktuasi harga cabai rawit), karena variabel-variabel independen berupa jumlah cabai, harga tomat, harga bawang merah, harga garam, harga terasi, musim dan harga input secara bersama-sama dapat mempengaruhi variabel Y yaitu anomali (fluktuasi harga cabai). Uji signifikansi pada model persamaan regresi terlihat pada Tabel 4.

\section{Tabel 4}

Anova untuk Pengujian Model Persamaan Regresi Linier Berganda ANOVA $^{\mathrm{a}}$

\begin{tabular}{|ll|c|c|c|c|c|}
\hline Model & Sum of Squares & df & Mean Square & F & Sig. \\
\hline 1 & Regression & 1841042725,412 & 7 & 263006103,630 & 2,557 &, $043^{\mathrm{b}}$ \\
& Residual & 2262823941,255 & 22 & 102855633,693 & & \\
& Total & 4103866666,667 & 29 & & & \\
\hline
\end{tabular}

a. Dependent Variable: Anomali

b. Predictors: (Constant), Input, Bawang, Terasi, Tomat, Jumlah, Musim, Garam

Data primer diolah SPSS (2019)

Besarnya pengaruh variabel-variabel jumlah cabai, harga tomat, harga bawang merah, harga garam, harga terasi, musim dan harga input terhadap variabel $\mathrm{Y}$ (anomali/ fluktuasi harga cabai) mencapai $44,9 \%$ sebagaimana ditunjukkan dari nila $R$ Square pada Tabel 5, sementara sekitar $55.1 \%$ disebabkan oleh variabel lain yang tidak masuk dalam objek penelitian. 
Tabel 5

Nilai Koefisien Determinasi pada Model Persamaan Regresi Linier Berganda Model Summary

\begin{tabular}{|c|c|c|c|c|}
\hline Model & $\mathrm{R}$ & $\mathrm{R}$ Square & Adjusted R Square & Std. Error of the Estimate \\
\hline 1 &, $670^{\mathrm{a}}$ &, 449 &, 273 & 10141,77665 \\
\hline
\end{tabular}

a. Predictors: (Constant), Input, Bawang, Terasi, Tomat, Jumlah, Musim, Garam

Data primer diolah SPSS (2019)

\section{Uji Parsial Persamaan Regresi Linier Berganda}

Berdasarkan hasil uji secara parsial dengan menggunakan uji $\mathrm{t}$, diperoleh gambaran bahwa pengaruh variabel jumlah cabai, harga tomat, harga bawang merah, harga garam, harga terasi, musim dan harga input terhadap variabel Y (anomali/fluktuasi harga cabai), diperoleh hasil sebagaimana terlihat pada Tabel 2. Berdasarkan hasil uji $\mathrm{t}$ terhadap variabel-variabel tersebut, maka variabel jumlah cabai dan varibel harga input yang dapat mempengaruhi variabel $Y$. Mengenai pengaruh dari setiap variabel bebas berdasarkan uji $\mathrm{t}$ dapat dijelaskan sebagai berikut:

1. Variabel jumlah cabai $\left(X_{1}\right)$ terhadap anomali/fluktuasi harga cabai rawit (Y).

Pengaruh variabel jumlah cabai rawit yang dijual $\left(\mathrm{X}_{1}\right)$ terhadap variabel anomali (Y), diperoleh nilai t Hitung sebesar 3,330 lebih besar (>) dibandingkan dengan nilai $\mathrm{t}$ Tabel yaitu sebesar 2,069, sehingga variabel jumlah cabai yang dijual di pasar $\left(\mathrm{X}_{1}\right)$ berpengaruh nyata terhadap variabel anomali (Y).

2. Variabel harga tomat $\left(\mathrm{X}_{2}\right)$ terhadap anomali/fluktuasi harga cabai rawit (Y). Pengaruh variabel harga tomat $\left(\mathrm{X}_{2}\right)$ terhadap anomali/fluktuasi harga cabai (Y), diperoleh nilai $\mathrm{t}$ Hitung sebesar 0,356 lebih kecil (<) dibandingkan dengan nilai $\mathrm{t}$ Tabel yaitu sebesar 2,069, sehingga variabel harga tomat $\left(\mathrm{X}_{2}\right)$ tidak nyata mempengaruhi variabel anomali (Y).

3. Variabel harga bawang merah $\left(\mathrm{X}_{3}\right)$ terhadap anomali/fluktuasi harga cabai rawit (Y). Pengaruh variabel harga bawang merah $\left(\mathrm{X}_{3}\right)$ terhadap variabel anomali (Y), diperoleh nilai t Hitung sebesar 0,284 lebih kecil (<) dibandingkan dengan nilai $\mathrm{t}$ Tabel yaitu sebesar 2,069, sehingga variabel harga bawang merah $\left(\mathrm{X}_{3}\right)$ tidak nyata mempengaruhi variabel anomali (Y).

4. Variabel harga garam $\left(\mathrm{X}_{4}\right)$ terhadap anomali/fluktuasi harga cabai rawit (Y). Pengaruh variabel harga garam $\left(\mathrm{X}_{4}\right)$ terhadap variabel anomali/fluktuasi harga cabai (Y), diperoleh nilai t Hitung sebesar 1,721 lebih kecil $(<)$ dibandingkan dengan nilai $\mathrm{t}$ Tabel yaitu sebesar 2,069, sehingga variabel harga garam $\left(\mathrm{X}_{4}\right)$ tidak nyata mempengaruhi variabel anomali (Y).

5. Variabel harga terasi $\left(\mathrm{X}_{5}\right)$ terhadap variabel anomali/fluktuasi harga cabai rawit (Y). Pengaruh variabel harga terasi $\left(\mathrm{X}_{5}\right)$ terhadap variabel anomali/fluktuasi harga cabai rawit (Y), diperoleh nilai t Hitung sebesar 0,782 lebih kecil $(<)$ dibandingkan dengan nilai t Tabel yaitu sebesar 2,069. Oleh karenanya variabel harga terasi $\left(\mathrm{X}_{5}\right)$ tidak nyata mempengaruhi variabel anomali (Y).

6. Variabel musim $\left(\mathrm{X}_{6}\right)$ terhadap variabel anomali/fluktuasi harga cabai rawit $(\mathrm{Y})$. Pengaruh variabel musim $\left(\mathrm{X}_{6}\right)$ terhadap variabel anomali (Y), diperoleh nilai t Hitung sebesar 1,893 lebih kecil dibandingkan dengan nilai $t$ Tabel yaitu sebesar 2,069, sehingga variabel musim $\left(\mathrm{X}_{6}\right)$ tidak nyata mempengaruhi variabel anomali (Y).

7. Variabel harga input $\left(\mathrm{X}_{7}\right)$ terhadap variabel anomali/fluktuasi harga cabai rawit (Y). Pengaruh variabel harga 
Input $\quad\left(\mathrm{X}_{7}\right) \quad$ terhadap variabel anomali/fluktuasi harga cabai rawit (Y), diperoleh nilai t Hitung sebesar 3,330 lebih besar (>) dibandingkan dengan nilai $\mathrm{t}$ Tabel yaitu sebesar 2,069, sehingga variabel harga input $\left(\mathrm{X}_{7}\right)$ nyata dapat mempengaruhi variabel anomali harga cabai rawit (Y).

\section{Pembahasan}

Untuk mengetahui lebih mendalam mengenai pengaruh variabel-variabel $(\mathrm{X})$ terhadap variabel (Y), maka hendak dilakukan pembahasannya, sebagai berikut:

\section{Pengaruh variabel jumlah cabai di pasaran $\left(X_{1}\right)$ terhadap anomali harga cabai rawit $(Y)$}

Secara umum jumlah cabai yang laku/terjual di pasar, menunjukkan jumlah permintaan yang sebenarnya akan cabai rawit. Kebutuhan cabai di pasar sebenarnya relatif tetap dan dapat diprediksi sesuai dengan permintaan para pembeli (pelanggan). Setiap pedagang cabai dapat menjual cabai rawit rata-rata $200,4 \mathrm{~kg}$ cabai per pedagang. Anomali/fluktuasi harga cabai merupakan fenomena naik turunnya harga cabai rawit, yang diukur dari selisih harga cabai rawit tertinggi dengan terendah yang terjadi selama satu tahun. Fluktuasi yang tinggi terjadi apabila selisih harga cabai rawit tertinggi dengan terendah tersebut tinggi, dan sebaliknya jika selisih harga cabai rendah, fluktuasinya dikatakan rendah. Berdasarkan hasil analisis regresi, semakin tinggi jumlah cabai rawit yang terjual untuk setiap pedagang, berpengaruh nyata terhadap semakin tingginya anomali/fluktuasi harga cabai rawit di pasar. Hal ini dikarenakan pengaruh $\mathrm{X}_{1}$ terhadap $\mathrm{Y}$ adalah positif. Fakta tersebut dapat di jelaskan berikut ini:

Cabai rawit merupakan produk yang tidak tahan lama dan mudah rusak Haryanti (2012), sementara kebutuhan masyarakat akan cabai rawit relatip tetap dan dapat diprediksi. Pada saat musim paceklik masyarakat tetap membutuhkan cabai dalam jumlah relatif sama, sehingga masyarakat akan tetap membeli cabai rawit walaupun harga tinggi. Setiap pedagang di pasar sudah memiliki pelanggan masing-masing baik pelanggan tetap yang setiap hari membeli cabai rawit maupun pelanggan tidak tetap, dengan kebutuhan cabai rawit yang jumlahnya dapat diprediksi. Setiap cabai rawit yang masuk ke pedagang di pasar, akan dijual dan didistribusikan kepada pelanggan tetap masing-masing maupun kepada pelanggan tidak tetap. Jika cabai rawit jumlahnya sedikit yang disebabkan gagal panen terkena musim kemarau atau terkena hama, maka pelanggan akan mendapat jatah yang juga lebih sedikit. Beberapa pelanggan, terutama pelanggan utama berani membayar lebih mahal jika memperoleh jumlah yang lebih banyak. Pada kondisi ini, permintaan jumlah cabai rawit yang lebih besar (excess demand) kepada pedagang akan dibayar dengan harga lebih tinggi oleh pelanggan, sehingga mengakibatkan fluktuasi harga cabai rawit di pasar juga tinggi. Peristiwa ini dapat dijelaskan pada Gambar 1. 


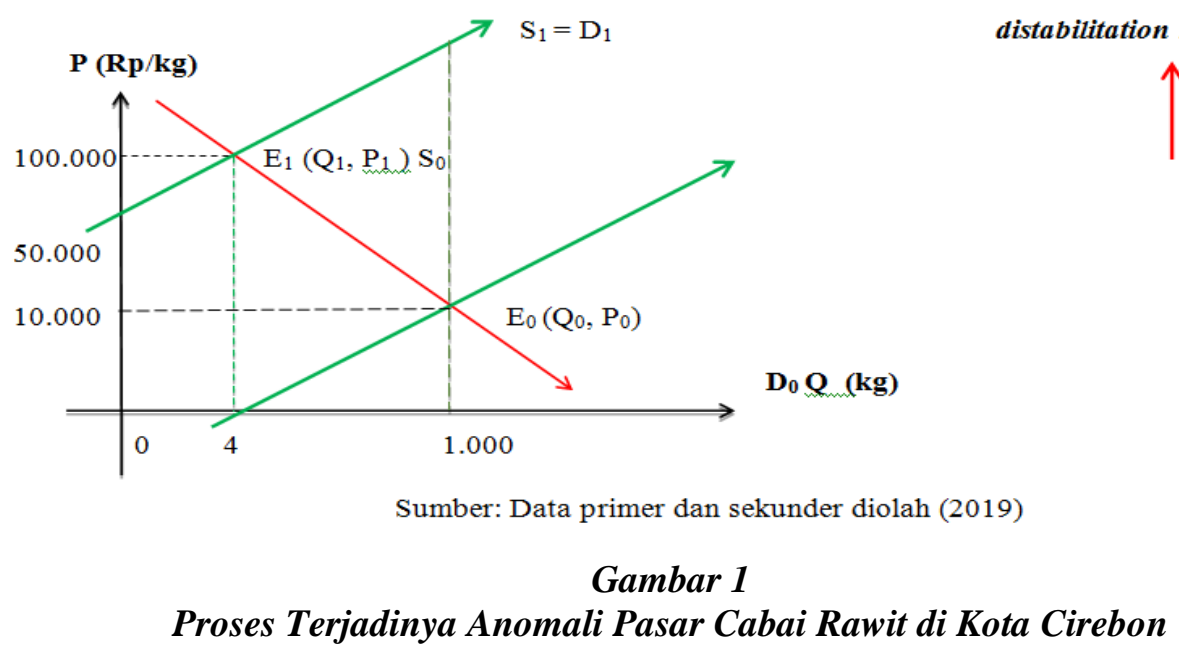

Gambar 1 menjelaskan bahwa semula harga keseimbangan $\left(\mathrm{P}_{\mathrm{o}}\right)$ cabai rawit berada pada Rp 10.000,-/kg dan jumlah keseimbangan di pasar $\left(\mathrm{Q}_{\mathrm{o}}\right)$ sebesar $1.000 \mathrm{~kg}$. Namun pada saat terjadi kelangkaan cabai rawit, misal karena gagal panen, maka jumlah yang dijual di pasar menurun menjadi $\left(\mathrm{Q}_{1}\right)$ sebesar $400 \mathrm{~kg}$ dan harga naik menjadi Rp $100.000,-/ \mathrm{kg}$ karena jumlah permintaan pasar relatif tetap. Semenjak kejadian tersebut $\left(E_{1}\right)$, maka jika jumlah cabai rawit dipasaran ditambah, maka akan diikuti juga dengan bertambahnya harga cabai rawit. Peristiwa inilah yang menjadi sebuah anomali karena kurva permintaan semula $\left(D_{0}\right)$ berubah menjadi kurva penawaran yang baru (S1=D1) (Sukirno, 2014), sehingga sepanjang terjadi penambahan jumlah cabai rawit yang dijual di pasaran (Q) maka akan mengakibatkan peningkatan harga cabai rawit sehingga fluktuasinya juga tinggi. Harga akan menjadi turun dan normal kembali pada saat penambahan cabai rawit mencapai $1.000 \mathrm{~kg}$ di pasaran. Hal ini dikarenakan kapasitas tidak berpengaruh nyata terhadap penawarannya, ini juga dapat dimaknai bahwa penawaraan (jumlah produksi) tidak mempengaruhi harga cabai rawit di Kota Salatiga, Jawa Tengah. Penelitian Ratnafurri (2012). Hasil penelitian lain yang juga bertentangan namun bersifat menambahkan faktor yaitu penelitian Haryanti (2012) yang menambahkan bahwa fluktuasi harga cabai merah di Kabupaten Sragen Provinsi Jawa Tengah disebabkan oleh faktor sifat dari komoditas cabai merah itu sendiri yaitu bersifat musiman. Sifat ini juga sama dengan sifat cabai rawit. Selain itu sifat tambahan lainnya yaitu: tidak tahan lama dan mudah rusak (cepat busuk). Kondisi ini diperkuat oleh hasil penelitian Saptana et al., (2012) yang menyimpulkan bahwa fluktuasi harga cabai merah yang tinggi di daerah sentra disebabkan fluktuasi produksi antar waktu (bulan dan musim), sedangkan Pardian et al., (2016) menambahkan bahwa kesenjangan (gap) antara pasokan (supply) dengan permintaan (demand) bawang merah di Provinsi Jawa Barat menyebabkan fluktuasi harga antar waktu. Hasil penelitian yang selaras maupun yang bertentangan tersebut menjadi sangat bermanfaat dalam rangka memperluas pengetahuan mengenai fenomena cabai rawit di tanah air, yang ternyata memiliki spesifikasi lokal sehingga tidak bisa digeneralisasi dalam permasalahannya. Oleh karena itu kebijakan yang hendak direkomendasikan 
melalui hasil penelitian ini juga bersifal lokal.

\section{Pengaruh biaya input $\left(X_{7}\right)$ terhadap anomali/fluktuasi harga cabai rawit $(Y)$}

Biaya input $\left(\mathrm{X}_{7}\right)$ pada usaha budidaya cabai rawit meliputi biaya pupuk, obat-obatan, sewa lahan dan tenaga kerja. Berdasarkan hasil analisis regresi, menunjukkan bahwa semakin besar biaya input $\left(\mathrm{X}_{7}\right)$ memberikan dampak semakin kecilnya fluktuasi harga cabai rawit (pengaruhnya negatif). Fakta tersebut dapat di jelaskan pada Gambar 2.

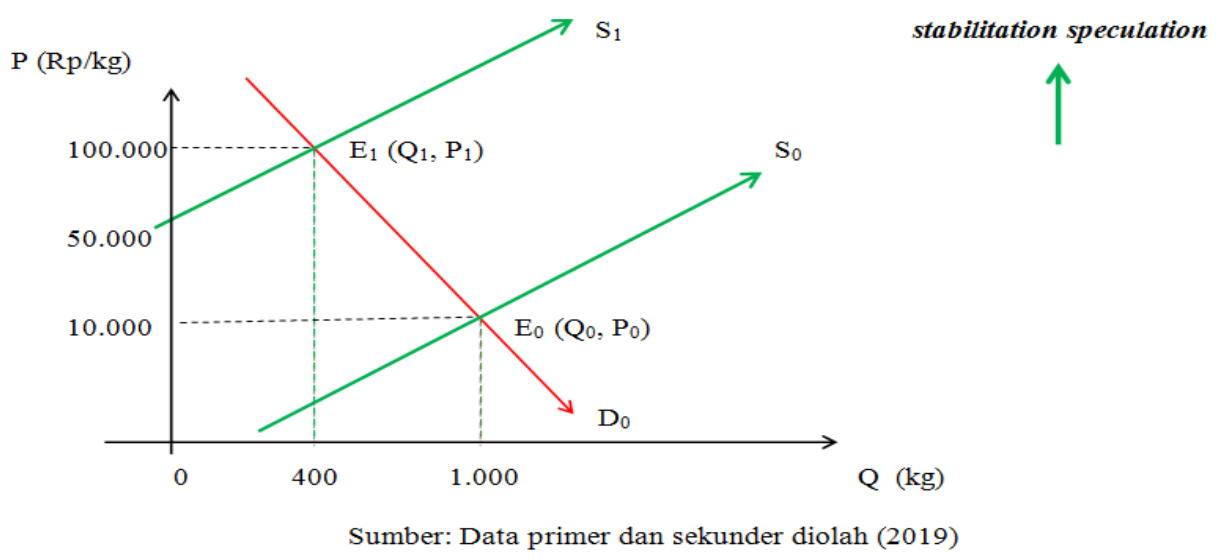

Gambar 2

Proses Terjadinya Anomali Pasar Cabai Rawit di Kota Cirebon $\left(X_{7}\right)$

Gambar 2 menunjukkan bahwa semula harga keseimbangan pasar cabai rawit $\left(\mathrm{E}_{\mathrm{o}}\right)$ pada harga $\left(\mathrm{P}_{\mathrm{o}}\right)$ sebesar $\mathrm{Rp} 10.000 / \mathrm{kg}$ dan jumlah keseimbangannya $\left(\mathrm{Q}_{\mathrm{o}}\right)$ sebesar 1.000 kg. Pada saat terjadi kelangkaan cabai rawit di pasaran yang dapat disebabkan oleh faktor gagal panen (karena kemarau atau serangan hama/penyakit), menjadikan jumlah cabai rawit $(\mathrm{Q})$ berkurang (misalkan menjadi $400 \mathrm{~kg}$ ) dan secara otomatis harga harga naik pada level tinggi yaitu menjadi $\mathrm{Rp} 100.000 / \mathrm{kg}$ atau terjadi kenaikkan yang spektakuler yaitu sebesar $1.000 \%$. Bersamaan hal tersebut ada sebagian petani yang berani melakukan penanaman cabai rawit dengan menambah biaya input (X7), misalnya menambah biaya pengairan (baik dengan tenaga manusia atau dengan mesin air). Penambahan biaya input bertujuan agar dapat panen cabai rawit sehingga ada penambahan produk cabai rawit di pasaran. Harapannya agar masih dapat menikmati harga yang sedang tinggi pada saat itu, walaupun sangat disadarinya bahwa dengan adanya penambahan produk cabai rawit secara terus menerus akan dapat menurunkan harga cabai rawit itu sendiri, akan tetapi harga tersebut masih di atas harga keseimbangan semula $\left(\mathrm{P}_{\mathrm{o}}\right)$, sehingga masih dapat meraih laba. Penambahan $Q$ berhenti pd saat $\mathrm{Q}=1.000 \mathrm{~kg}$ karena jika ditambah terus akan mengalami kerugian karena harga cabai rawit (P) di pasaran yang sudah menurun. Akibatnya jika biaya input (X7) bertambah akan mengakibatkan fluktuasi harganya (anomali) akan berkurang karena pengaruh $\mathrm{X} 7$ terhadap $\mathrm{Y}$ adalah negatif. Peristiwa ini termasuk spekulasi yang menstabilkan perekonomian daerah (stabilitation speculation) (Sukirno, 2014).

Hasil penelitian ini bertentangan dengan penelitian Ratnafurri dan Emma Wahyu (2012) yang menyimpulkan bahwa penambahan input (pupuk SP-36) berpengaruh positif terhadap penawaran cabai rawit di Kota Salatiga Provinsi Jawa Tengah. Arti implementatifnya jika penggunaan input (pupk SP-36) meningkat maka akan meningkatkan harga cabai rawit 
tersebut, sedangkan di Kota Cirebon tidak demikian, yaitu jika penggunaan input naik, dan berdampak pada penambahan produksi cabai, maka akan menurunkan harga cabai rawitnya. Hasil penelitian Ratnafurri (2012) juga selaras dengan hasil penelitian Maemunah et al. (2019) yang menyatakan bahwa penggunaan input (pupuk ZA) berpengaruh nyata terhadap peninggkatan produksi cabai rawit di Kabupaten Magelang, Jawa Tengah, artinya juga berpengaruh terhadap peningkatan penawarannya.

Perbedaan hasil penelitian ini dimungkinkan karena usahatani cabai rawit dan atau cabai merah di Kota Salatiga dan Kabupaten Magelang pada umumnya dilakukan secara lebih intensif, sedangkan di Kota Cirebon dari aspek usahataninya dilakukan secara musiman (tadah hujan), sehingga kekurangan pasokan cabai rawit di Kota Cirebon lebih banyak dipasok dari luar daerah. Akibatnya dengan faktor yang sama yaitu penambahan produksi dapat mengarah kepada dua sifat, yaitu penambahan produksi cabai rawit yang melabilkan perekonomian (pasokan yang datang dari luar atau oleh spekulator) dan penambahan produksi yang menstabilkan perekonomian (pasokan yang datang dari regional/lokal Kota Cirebon/internal). Untuk itu diperlukan upaya bagaimana usahatani di regional Cirebon lebih intensif sehingga jika kekurangan pasokan cabai rawit cukup dipasok dari daerah sekitar, tanpa harus mendatangkan dari luar daerah, sehingga aspek spekulasinya minimum (Sukirno, 2014).

\section{Harga produk komplementer terhadap anomali/fluktuasi harga cabai rawit}

Produk komplementer cabai rawit dalam penelitian ini, yaitu: bawang merah, garam, tomat dan terasi. Pemanfaatan produk komplementer dengan cabai rawit biasanya untuk produk olahan berupa sambal, dan bumbu masakan lainnya. Berdasarkan hasil analisis regresi, harga produk komplementer tersebut tidak mempengaruhi anomali/fluktuasi harga cabai rawit di pasaran. Kondisi yang demikian dapat dijelaskan berikut ini:

a. Produksi yang berbeda.

Produksi bawang merah, garam, tomat dan terasi tidak terkait dengan produksi cabai rawit. Terasi dan garam merupakan produk yang dihasilkan dari proses pengolahan standarisasi dari bahan baku tertentu. Produk yang dihasilkan umumnya sesuai dengan perencanaannya, baik jumlah maupun kualitas sehingga harga jual juga sudah bisa diprediksi dan relatif stabil. Sementara untuk bawang merah, kendatipun termasuk dalam produk yang dihasilkan dari proses budidaya seperti halnya cabai rawit, akan tetapi pola produksinya sangat berbeda. Bawang merah memiliki syarat tumbuh, proses budidaya, musim, teknologi, dan tingkat kerumitan yang berbeda dengan tanaman cabai rawit, sehingga proses produksi bawang merah tidak mengikuti atau memperhatikan cabai rawit. Pada saat produksi bawang merah melimpah dan harga yang rendah, bisa saja harga cabai rawit sedang tinggi atau sebaliknya harga cabai sedang rendah. Demikian juga dengan tomat yang sangat mirip dengan bawang merah dalam proses produksinya.

b. Tujuan penggunaan yang berbeda-beda. Bawang merah, dan garam kendatipun dapat sebagai komplementer dengan cabai rawit, akan tetapi memiliki fungsi dan tujuan penggunaan tersendiri yang jauh lebih besar dibandingkan sebagai komplementer. Bawang merah dapat dijadikan sebagai input industri bawang goreng yang bisa digunakan untuk penyedap masakan. Garam memilki banyak penggunaan lain sebagai garam industri yang merupakan input pada 
industri manufaktur maupun pengolahan makanan.

c. Mempunyai daya simpan yang lebih lama.

Bawang merah, garam dan terasi merupakan produk komplementer yang dapat disimpan dan memiliki umur simpan yang lebih jauh lama dibandingkan cabai rawit. Bawang merah dapat disimpan hingga mencapai tiga bulan pada suhu kamar, sementara garam dan terasi dapat disimpan lebih dari satu tahun, sehingga harga produk komplementer relatif stabil sepanjang tahun. Dengan demikian naik turunnya harga cabai rawit bukan disebabkan oleh harga dari produk komplementer tersebut. Namun demikian, terkait dengan daya simpan maka cabai rawit juga dapat disimpan pada ruang pendingin bersuhu $4 \quad{ }^{\circ} \mathrm{C}$ guna memperpanjang kesegaran cabai rawit karena pada suhu tersebut dapat menekan tingkat perkembangan mikroorganisme dan perubahan biokimia (Asgar, 2009 dalam Anwarudin S., 2015).

Hasil penelitian yang menyimpulkan bahwa harga barang komplementer tidak berpengaruh nyata terhadap harga cabai rawit ini, bertentangan dengan hasil penelitian Palar et al., (2016) yang menyimpulkan bahwa harga barangbarang komplementer (tomat) berpengaruh nyata dan berbanding terbalik (negatif) terhadap kenaikkan harga cabai rawit di Kota Manado, Sulawesi Utara. Perbedaan ini lebih dikarenakan sifat komoditas pertanian (cq. cabai rawit dan tomat) yang sudah memiliki kekhasan dari tiap-tiap daerah di seluruh penjuru tanah air, artinya di Kota Manado kedudukan tomat lebih superior dari pada cabai rawit, tetapi di Kota Cirebon kedudukan cabai rawit yang lebih superior dari pada tomat (Sukirno, 2014).

\section{Pengaruh musim $\left(X_{6}\right)$ terhadap anomali/fluktuasi harga cabai rawit (Y)}

Musim disini adalah musim paceklik (kemarau) dan musim panen (penghujan), berdasarkan hasil analisis regresi, musim tidak mempengaruhi anomali/fluktuasi harga cabai rawit. Hal ini bisa dijelaskan berikut ini:

a. Harga tinggi disebabkan karena kelangkan cabai.

Kelangkaan cabai bukan disebabkan oleh faktor musim semata, tetapi karena petani enggan menanam cabai rawit di lahan non sawah karena adanya resiko gagal yang tinggi dan biaya produksi yang tinggi (Anwarudin S., et al., 2015). Oleh karenya musim tidak berpengaruh nyata terhadap anomali atau fluktuasi harga cabai rawit. Hal ini berbeda dengan komoditas bawang merah dimana fluktuasi harganya dikerenakan oleh musim (Pardian et al., 2016), dan berbeda juga dengan komoditas cabai merah yang fluktuasi harganya dipengaruhi oleh musim (Saptana et al., 2012; dan Haryanti, 2012).

b. Kebutuhan cabai yang meningkat pada hari besar dan tahun baru.

Pada hari raya dan tahun baru biasanya kebutuhan cabai akan meningkat sehingga harga cabai juga cenderung meningkat. Ini sesuai dengan hukum permintaan (the law of demand). Akan tetapi jika stok melimpah kenaikan harga cabai tidak terjadi, walaupun akan menghadapi hari-hari besar (raya). Konsumen tetap membelinya namun tetap dalam jumlah yang sesuai dengan kebutuhannya, artinya tidak menstok cabai rawit dalam jumlah banyak untuk kebutuhan mendatang. Inilah ciri-ciri bahwa komoditas pertanian pada umumnya (termasuk cabai rawit) bersifat inelastis, artinya walaupun 
harga turun atau naik, maka konsumen tetap membeli sesuai dengan kebutuhan setiap harinya (Wachdijono, 2020).

Memperhatikan hasil analisis di atas, dimana hanya ada dua faktor (variabel) yang berpengaruh nyata terhadap anomali pasar cabai rawit di kota Cirebon, yaitu faktor jumlah produk $\left(\mathrm{X}_{1}\right)$ dan faktor biaya input $\left(\mathrm{X}_{7}\right)$. Kedua faktor tersebut saling bertentangan, yaitu jika $\mathrm{X}_{1}$ ditambah akan memperbesar fluktuasi harga (anomali), akan tetapi jika $\mathrm{X}_{7}$ ditambah (yang juga berdampak pada penambahan $\mathrm{Q}$ ) justeru akan mengurangi fluktuasi harga cabai rawit. Untuk menentukan faktor mana yang dapat dijadikan saran (rekomendasi) nantinya, maka digunakan pedoman nilai elastisitas, yaitu nilai elastisitas (koefisien regresinya) yang lebih tinggi. Oleh karenanya yang relevan dan logis untuk dijadikan saran adalah faktor penambahan biaya input $\left(X_{7}\right)$. Hal ini dikarenakan dengan penambahan biaya input $\left(\mathrm{X}_{7}\right)$ akan berdampak pada penurunan fluktuasi harga cabai rawit yang disebabkan oleh aspek internal (sumberdaya lokal) sehingga cenderung pada terciptanya unsur spekulasi yang menstabilkan perekonomian. Akan tetapi jika faktor $\mathrm{X}_{1}$ yang ditambah, dimana sangat berpeluang untuk mendatangkan cabai rawit dari luar daerah Cirebon (misal dari Jawa Timur, Bali dan Nusa Tenggara) sehingga akan sangat berpotensi/kecenderungan pada terciptanya unsur spekulasi yang melabilkan perekonomian daerah. Artinya penambahan cabai rawit di pasaran dapat diatur oleh pihak-pihak yang ingin meraup laba yang tinggi (spekulator) pada saat paceklik, dengan membangun opini kepada pelaku usaha yang lain, bahwa harga cabai rawit di pasaran akan selalu naik dari hari ke hari sehingga orang akan selalu berebut untuk mendapatkan cabai rawit dengan harapan akan dapat dijual lagi di pasaran dengan laba yang lebih tinggi (Sukirno, 2014).

\section{Kesimpulan}

Berdasarkan hasil penelitian dan pembahasan di atas, dapat diambil suatu kesimpulan bahwa secara simultan faktorfaktor yang mempengaruhi anomali/fluktuasi pasar cabai rawit di kota Cirebon yaitu jumlah cabai rawit yang dijual di tingkat pengecer, harga tomat, harga bawang merah, harga garam, harga terasi, musim dan harga input di tingkat petani cabai rawit. Adapun secara parsial yang berpengaruh yaitu faktor jumlah cabai rawit yang dijual di tingkat pengecer dan faktor harga input. Untuk menurunkan fluktuasi harga (anomali) cabai rawit di kota Cirebon lebih disarankan pada penerapan faktor penambahan biaya input, yang dapat dilakukan melalui upaya gerakan bersama menanam cabai rawit di masyarakat kota pada khususnya dan adanya upaya bantuan mesin air atau membuat embung pada daerah atau sentra produksi serta adanya upaya pengawetan cabai melalui pengadaan mesin pendingin yang didirikan dekat pasarpasar besar di kota Cirebon. Upaya tersebut dapat diwujudkan melalui adanya kebijakan yang diprakarsasi oleh Pemerintah Kota Cirebon melalui dinas terkait, yaitu Dinas Pangan Pertanian Perikanan dan Kelautan (DP3K) Kota Cirebon.

\section{Ucapan Terima Kasih}

Ucapan terima kasih yang sebesar-besarnya disampaikan kepada Kementerian Riset, Teknologi dan Pendidikan Tinggi RI yang telah membiayai penelitian ini pada tahun 2019.

\section{Daftar Pustaka}

Anwarudin S., M. Jawal., Apri L. Sayekti, Aditia Marendra K., dan Yusdar Hilman. 2015. Dinamika Produksi dan Volatilitas Harga Cabai: Antisipasi Strategi Dan Kebijakan Pengembangan. Jurnal Pengembangan Inovasi Pertanian Vol. 8 No. 1: 33-42. Badan 
Penelitian dan Pengembangan Pertanian Kementerian Pertanian RI. Jakarta.

Badan Pusat Statistik (BPS). 2017. Jakarta.

Gilarso, T. 2007. Pengantar Ilmu Ekonomi Mikro, Kanisius, Yogyakarta.

Haryanti, Titik. 2012. Analisis Perilaku Harga Dalam Pemasaran Cabai Merah di Kabupaten Sragen. Skripsi Fakultas Pertanian Universitas Sebelas Maret (UNS). Solo.

Juniarsih, Triara. 2016. Faktor-Faktor Yang Mempengaruhi Harga Cabai Merah (Capsicum Annuum L.) di Sumatera Utara. Tesis Program Studi Magister Agribisnis Fakultas Pertanian Universitas Sumatera Utara. Medan

Maemunah, Nila, Bambang Mulyatno S dan Agus Setiadi. 2019. Analisis Efisiensi Penggunaan Faktor-Faktor Produksi Usahatani Cabai Rawit di Desa Girikulon Kecamatan Secang Kabupaten Magelang. Jurnal Agroland Fakultas Pertanian Universitas Tadulako. 26 (2) : $96-110$. Palu.

Nurvitasari, Maya Eka, Anik Suwandari dan Luh Putu Suciati. 2018. Dinamika Perkembangan Harga Komoditas Cabai Merah (Capsicum Annuum L) di Kabupaten Jember. Jurnal Sosial Ekonomi Pertanian Vol 11 No. 1 Fakultas Pertanian Universitas Jember. Jember

Palar, Nathania, Paulus A. Pangemanan dan Ellen G. Tangkere. 2016. Faktor-Faktor Yang Mempengaruhi Harga Cabai Rawit di Kota Manado. Jurnal Agrisosioekonomi-Volume 12 Nomor 2 : 105 - 120. Manado.

Pardian, Pandi, Trisna Insan Noor dan Achdya Kusumah. 2016. Analisis Penawaran Dan Permintaan Bawang Merah di Provinsi Jawa Barat.
AGRICORE-Jurnal Agribisnis dan Sosial Ekonomi Pertanian Universitas Pajajaran Bandung. Vol. 1, No. 2, hal: 95-204. Bandung.

Pusat Data dan Sistem Informasi Pertanian

Sekretariat Jenderal Kementerian Pertanian Tahun 2015-2019.

Rahmah, Aulia, Mia Rosmiati, dan Angga Dwiartama. 2017. Rantai Pangan Berkelanjutan: Kasus Komoditas Cabai Di Kabupaten Garut. AGRICOREJurnal Agribisnis dan Sosial Ekonomi Pertanian Universitas Pajajaran Bandung. Vol. 2 No. 1: 205-290. Bandung.

Ratnafurri dan Emma Wahyu. 2012. Analisis Penawaran Cabai Rawit di Kota Salatiga. Skripsi Fakultas Pertanian Universitas Sebelas Maret Surakarta (UNS). Solo.

Riduan. 2011. Dasar-Dasar Statistik, Alfabeta, Bandung

Riyadh, Muhammad Ilham, Dian Hendrawan, Jhony Manutur Silalahi. 2018. Analisis Pergerakan Harga Cabai Dan Bawang di Kota Medan. Jurnal Kajian Ekonomi dan Kebijakan Publik Vol. 4 No. 1. Medan.

Sugiyono. 2017. Metode Penelitian Kuantitatif, Kualitatif dan R \& D, Alfabeta, Bandung,

Sukirno, Sadono. 2014. Mikroekonomi Teori Pengantar Edisi Ketiga. PT. RajaGrafindo Persada. Jakarta.

Wachdijono. 2020. Sifat Elastisitas Permintaan Cabai Rawit Dalam Dua Kondisi Perubahan Harga di Kota Cirebon. Composite. Jurnal Ilmu-Ilmu Pertanian.. Vol. 2 No. 1 hal:1-10. Universitas Insan Cendekia MandiriUNBAR. Bandung. 